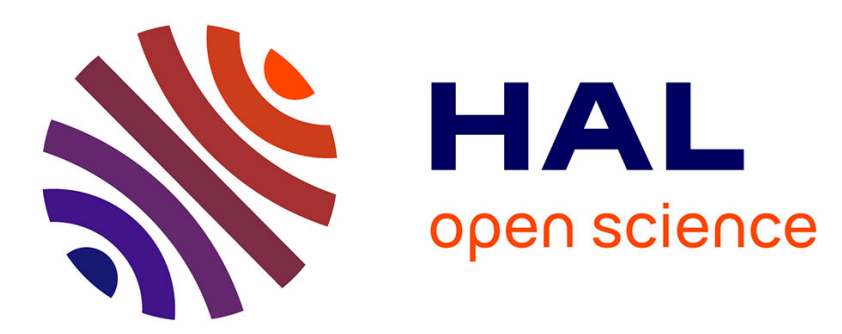

\title{
Revisiting the existence of an effective stress for wet granular soils with micromechanics
}

Jérôme Duriez, Richard Wan, Mehdi Pouragha, Félix Darve

\section{To cite this version:}

Jérôme Duriez, Richard Wan, Mehdi Pouragha, Félix Darve. Revisiting the existence of an effective stress for wet granular soils with micromechanics. International Journal for Numerical and Analytical Methods in Geomechanics, 2018, 42 (8), pp.959-978. 10.1002/nag.2774 . hal-02015650

\author{
HAL Id: hal-02015650 \\ https://hal.science/hal-02015650
}

Submitted on 12 Feb 2019

HAL is a multi-disciplinary open access archive for the deposit and dissemination of scientific research documents, whether they are published or not. The documents may come from teaching and research institutions in France or abroad, or from public or private research centers.
L'archive ouverte pluridisciplinaire HAL, est destinée au dépôt et à la diffusion de documents scientifiques de niveau recherche, publiés ou non, émanant des établissements d'enseignement et de recherche français ou étrangers, des laboratoires publics ou privés. 


\title{
Revisiting the existence of an effective stress for wet granular soils with micromechanics
}

\author{
Jérôme Duriez, Richard Wan, Mehdi Pouragha and Félix Darve
}

\begin{abstract}
A possible effective stress variable for wet granular materials is numerically investigated based on an adapted Discrete Element Method (DEM) model for an ideal three-phase system. The DEM simulations consider granular materials made of nearly monodisperse spherical particles, in the pendular regime with the pore fluid mixture consisting of distinct water menisci bridging particle pairs. The contact force-related stress contribution to the total stresses is isolated and tested as the effective stress candidate for dense or loose systems. It is first recalled that this contact stress tensor is indeed an adequate effective stress that describes stress limit states of wet samples with the same Mohr-Coulomb criterion associated with their dry counterparts. As for constitutive relationships, it is demonstrated that the contact stress tensor used in conjunction with dry constitutive relations does describe the strains of wet samples during an initial strain regime, but not beyond. Outside this so-called quasistatic strain regime, whose extent is much greater for dense than loose materials, dramatic changes in the contact network prevent macro-scale contact stress-strain relationships to apply in the same manner to dry and unsaturated conditions. The presented numerical results also reveal unexpected constitutive bifurcations for the loose material, related to stick-slip macro-behavior.
\end{abstract}

\section{Introduction}

The presence of pore fluids in soils is ubiquitously encountered in geomechanics and the change in mechanical behavior that ensues has been well recognized as far back as the pioneering work of K. von Terzaghi [1]. The fully saturated case first studied by Terzaghi is well understood now, while the more common case of partially saturated (unsaturated) soils has been the subject of longstanding investigation ever since Bishop's work [2]. A notorious difficulty in describing unsaturated soil behavior stems from the variety of internal forces to be considered and the related stress variables for a given volume. The details of interactions comprise distinct fluid pressures existing within the fluid volumes, as well as surface tension forces along the interfaces between phases, in addition to contact forces between solid grains. All these stress contributions eventually 
add up to form the total internal stresses, $\boldsymbol{\Sigma}$, that are necessarily in equilibrium with the external loads applied on the boundaries of the system $[3,4,5]$.

In line with Terzaghi's description of the saturated case, it would be of a great value to also identify, if it exists, a 'unique' so-called effective stress variable, $\boldsymbol{\sigma}^{\prime}$, that would govern both deformational and failure aspects of partially saturated soils through classic constitutive equations. In its strongest form which is investigated herein, the effective stress principle also implies that the effective stress variable must apply to partially saturated conditions through exactly the same constitutive equations derived in the dry case. This strong form where a unique shear strength criterion and constitutive equation would apply was indeed demonstrated by Terzaghi [1] and Biot [6] for both dry and saturated conditions.

Some promising results have been obtained along the above line of thought with numerical and experimental results unifying stress limit states observed in both dry and unsaturated conditions under the same failure criteria $[7,8,9$, $10,11,12,13]$. Such results could be obtained by separating the total stresses into two parts: (1) a fluid mixture stress contribution often denoted as suction stresses [9], and (2) a solid phase-related stress contribution which becomes the appropriate variable to describe stress limit states. Note that for granular soils, suction stresses can be identified with capillary stresses, $\sigma^{\text {cap }}$, since physico-chemical forces are negligible, whereas the solid-phase stress contribution encompasses grain-grain contact forces only, and is thus denoted herein as contact stress, $\sigma^{\text {cont }}[14,11,5]$.

However, it appears that an effective stress principle that would fully unify the behaviors of biphasic and triphasic soils may be too strong to hold. For instance, no unique strain-effective stress relationship could be identified from dry and unsaturated conditions in [10], even though strains in soils are defined from the solid phase strains [15], irrespective of what the saturation is in the pores. In fact, for granular materials, these solid phase strains are readily calculated from grain displacements along samples boundaries that encapsulate the effect of every type of internal forces for any saturation. Despite this, as a means to circumvent the effective stress principle, alternative approaches with two stress variables have been proposed to describe partially saturated soils using two sets of constitutive relations that separately apply to the net total stress and another stress variable such as matric suction $[16,17]$. A possible consensus to the debate has nevertheless been proposed in $[8,18]$, stating that the effective stress principle would still apply to unsaturated soils to describe their failure and elastic behavior, as limited as it is.

It is proposed herein to lend further support to this consensus proposal from a numerical micro-mechanical modeling exercise that will focus into the above-mentioned contact stress $\boldsymbol{\sigma}^{\text {cont }}$ as an effective stress candidate, using the Discrete Element Method (DEM). While previously mentioned works most often rely on experimental or phenomenological approaches, the DEM clearly constitutes another valuable approach, given the major role played by microstructure in the macro-behavior, and considering that DEM may provide a direct access to evaluate $\sigma^{\text {cont }}$ while experimental measurements of the latter are still under 
development [19]. As such, the DEM has previously been adapted to unsaturated conditions adopting a pore-scale description of the fluids distribution and additional interaction laws between Discrete Elements (DE's) to mimic the mechanical actions due to the fluid mixture [20,14, 21, 12], which contributed to elucidate the nature of stresses in partially saturated granular soils $[14,22,5]$ and the strength enhancements caused by unsaturation $[21,12,11]$. However, DEM has been relatively little used to elucidate the stress-strain behavior of unsaturated soils in an effective stress framework, apart from a preliminary analysis in [11]. It is thus proposed herein to test and demonstrate that the contact stress $\sigma^{\text {cont }}$ also displays a stress-strain effective nature for the initial strain behavior in addition to its already known stress-strength character, i.e. that early stage deformations in unsaturated dense and loose granular systems may be predicted from the constitutive relations of similar dry materials and the contact stress.

To achieve this goal, Section 2 presents an existing DEM model [12] and details of the sample generation procedure for dense or loose idealized granular materials. The precision of the DEM results is necessarily assessed in Section 3; in particular, unexpected constitutive bifurcations for loose materials are briefly discussed. Then, Section 4 confirms that the contact stress, $\sigma^{\text {cont }}$, may serve as an effective stress to describe granular material failure under unsaturated conditions in a manner consistent with dry conditions. Finally, the possible effective nature of $\sigma^{\text {cont }}$ and its ability in describing the stress-strain constitutive behaviors of dense and loose packings are thoroughly investigated in Section 5 .

\section{Micro-mechanical description of wet granular materials}

\subsection{Micro-mechanical stress description}

It is well-known that fine granular soils in unsaturated conditions include various internal forces at the microscopic scale - for instance, distinct air and water pressures, $u_{a}$ and $u_{w}$ with $u_{a}>u_{w}$ due to air-water surface tension $\gamma$ and small pore sizes. This pressure difference, defined as the capillary pressure $u_{c}$, can also be identified to the suction $s$ developed in granular materials, i.e.

$$
s=u_{c}=u_{a}-u_{w}
$$

In the general case, following a rather comprehensive microscopic treatment $[3,22,5]$ which involves homogenization, the macroscopic stress expression for unsaturated granular materials emerges and can be formally written in terms of the microscopic internal forces at hand:

$\boldsymbol{\Sigma}=\frac{1}{V}\left[\sum_{c} \vec{f}^{c} \otimes \vec{l}-s\left(V_{w} \boldsymbol{\delta}+\int_{S_{s w}} \vec{n} \otimes \vec{x} d S\right)-\gamma\left(\int_{S_{a w}}(\boldsymbol{\delta}-\vec{n} \otimes \vec{n}) d S+\int_{\Gamma} \vec{\nu} \otimes \vec{x} d l\right)\right]$ 
Eq. (2), herein coined as the $\mu$ UNSAT equation, is valid under quasistatic conditions and considering the air pressure $u_{a} \boldsymbol{\delta}$ as a zero-reference for the total stress $\boldsymbol{\Sigma}$. Various stress contributions enter this $\mu$ UNSAT equation and can be identified as follows:

- contact forces $\vec{f}^{c}$, with $\vec{l}$ the branch vector linking the contacting particle centroids;

- suction internal forces within the water volume $V_{w}$ and along the wetted solid surfaces $S_{s w}$ being oriented by $\vec{n}$ and described by $\vec{x}$ locations, measured from each particle centroid; and

- air-water surface tension internal forces that occur both within the airwater interface $S_{a w}$ and along solid-air-water contact lines $\Gamma$ where $S_{a w}$ meets the solid surface along direction $\vec{\nu}[5]$.

Restricting ourselves to idealized granular materials consisting of polydispersed spherical solid particles and to low water contents, the distribution of air and water conforms with a pendular-regime state with distinct water menisci bonding distinct spherical particle pairs (Fig. 1). Such a capillary bridge distri-

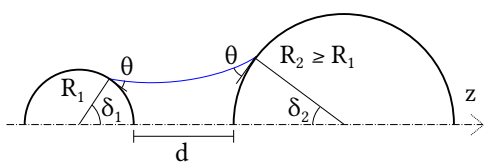

Figure 1: Water meniscus between a particle pair (half-view)

bution is specific to very low saturation regimes, up to roughly $5-10 \%$ degree of saturation, $S_{r}$, defined as:

$$
S_{r}=\frac{V_{w}}{V_{v}}=\frac{V_{w}}{V-V_{s}}
$$

with $V, V_{s}, V_{v}, V_{w}$ being respectively the total volume, the volume of the solid phase made of distinct particles, the voids volume, and the water phase volume.

In the pendular regime, all internal forces reduce to pair-wise interaction forces: contact forces $\vec{f}^{c}$ or resultant capillary forces $\vec{f}^{c a p}$ acting at every contact $c$ or meniscus $m$. As such, the total stresses, $\boldsymbol{\Sigma}$, may here be also expressed in terms of these interaction forces, according to the virial theorem [23, 24]:

$$
\Sigma=\frac{1}{V} \sum_{c} \vec{f}^{c} \otimes \vec{l}+\frac{1}{V} \sum_{m} \vec{f}^{c a p} \otimes \vec{l}
$$

Indeed, it has been demonstrated that both Eq. (2) and Eq. (4) are fully equivalent in the pendular regime so that the capillary stress, $\sigma^{c a p}$, may be indistinctly expressed using either fluid and interface internal forces, or resultant capillary 
forces $[3,22,25,5]$ :

$$
\begin{aligned}
\sigma^{c a p} & =-\frac{1}{V}\left[s\left(V_{w} \delta+\int_{S_{s w}} \vec{n} \otimes \vec{x} d S\right)+\gamma\left(\int_{S_{a w}}(\boldsymbol{\delta}-\vec{n} \otimes \vec{n}) d S+\int_{\Gamma} \vec{\nu} \otimes \vec{x} d l\right)\right] \\
& =\frac{1}{V} \sum_{m} \vec{f}^{c a p} \otimes \vec{l}
\end{aligned}
$$

On the other hand, a solid phase contribution to the stress state of wet granular materials can be identified in Eq. (2) or (4) as the contact stress tensor $\sigma^{\text {cont }}$, i.e.

$$
\sigma^{\text {cont }}=\frac{1}{V} \sum_{c} \vec{f}^{c} \otimes \vec{l}=\mathbf{\Sigma}-\sigma^{c a p}
$$

While the contact stress tensor obviously coincides with the total stresses in dry granular samples, it also appears to be an adequate effective stress-strength variable for describing failure in wet samples in $[11,12]$. Further investigations also regarding its effective nature with respect to stress-strain constitutive description are carried out in the next sections from a micro-mechanical DEM model that allows Eq. (2) or (4) to be used whereby the contact stress can be readily isolated and subsequently related to strains, given pertinent information on the microstructure.

In relation with the consideration of axisymmetric loading paths, with the direction 1 as the axis of symmetry and serving as one of the principal directions, the classical stress invariants $p, q$ and $\eta$ are used in addition to individual components to describe stress tensors $\boldsymbol{\Sigma}$ and $\sigma^{\text {cont }}$, i.e.

$$
\begin{gathered}
p=\frac{\Sigma_{1}+\Sigma_{2}+\Sigma_{3}}{3}=\frac{\Sigma_{1}+2 \Sigma_{3}}{3} \quad, \quad p^{\text {cont }}=\frac{\sigma_{1}^{\text {cont }}+\sigma_{2}^{\text {cont }}+\sigma_{3}^{\text {cont }}}{3}=\frac{\sigma_{1}^{\text {cont }}+2 \sigma_{3}^{\text {cont }}}{3} \\
q=\Sigma_{1}-\Sigma_{2}=\Sigma_{1}-\Sigma_{3} \quad, \quad q^{\text {cont }}=\sigma_{1}^{\text {cont }}-\sigma_{2}^{\text {cont }}=\sigma_{1}^{\text {cont }}-\sigma_{3}^{\text {cont }}
\end{gathered}
$$

\subsection{DEM modelling of wet granular materials}

Fitting our purpose, a previously proposed DEM model [12], built within the YADE open-source code [26], outputs a comprehensive description of the microstructure of wet granular materials, allowing all stress contributions to be measured explicitly from Eq. (2) or (4). According to the classical DEM computation cycle, particle relative displacements caused by contact and capillary forces are also determined, hence the strains in dry or wet conditions.

In order to reproduce wet conditions in the model sample, liquid bridges are created at each new grain-grain contact, consistent with experimental observations [27]. Furthermore, uniform air and water pressures (i.e. a uniform capillary pressure $u_{c}$ ) are considered throughout the samples, in line with thermodynamic equilibrium and another DEM model [14]. As such, liquid bridge geometries are computed solving the Laplace-Young equation for given values 
of $u_{c}=s$ and the contact angle $\theta$ (Fig. 1). The capillary interaction between capillary bonded DE's is then fully determined with the capillary interaction force $\vec{f} c a p$ expressed in terms of $\gamma, s, \theta$, the particle radii $R_{1}, R_{2}$ and the filling angles $\delta_{1}, \delta_{2}$ (Fig. 1):

$\vec{f}^{c a p}=\pi R_{1} \sin \delta_{1}\left(s R_{1} \sin \delta_{1}+2 \gamma \sin \left(\theta+\delta_{1}\right)\right) \vec{z}=\pi R_{2} \sin \delta_{2}\left(s R_{2} \sin \delta_{2}+2 \gamma \sin \left(\theta+\delta_{2}\right)\right) \vec{z}$

In the event that previously contacting particles separate, capillary interaction continues until the interparticle distance $d$ reaches a limit value, as a function of $s, \theta$ and the radii, beyond which the Laplace-Young equation does not yield a solution anymore. In such an instance, the meniscus breaks and the capillary interaction is lost. All menisci creation and rupture occur in the model in a fully drained manner, the water content and saturation ratio possibly evolving during constant suction loading, see [12] for more details.

In addition to the capillary interaction described in the above, a contact interaction is also applied between touching particles. Classical simplified contact laws link contact forces $\vec{f}^{c}$ to particle relative displacements, with a repulsive linear elastic behavior relating the normal contact force to the normal relative displacement, while a linear elastic-plastic relationship describes the tangential movement.

All DEM model parameters are listed in Table 1. Three of them are required to describe the contact interaction: a local Coulombian friction coefficient $\mu=\tan (\varphi)$ and two other parameters, $k_{n} / \bar{D}$ and $k_{t} / k_{n}$, giving the local elastic stifnesses $k_{n}, k_{t}$ from the average particle diameter $\bar{D}$. Additional model parameters relate to the capillary interaction, such as the particle size distribution which is chosen herein as uniform in number between silt-like extreme diameters $D_{\min }$ and $D_{\max }$. Also, the value of air-water surface tension at ambient temperature is retained for $\gamma$ while a small, though not zero, contact angle $\theta$ is considered to enhance the mechanical effects of unsaturation [12] and facilitate the analysis.

Table 1: DEM model parameters

\begin{tabular}{ccccccc}
\hline $\begin{array}{c}k_{n} / D \\
(\mathrm{MPa})\end{array}$ & $\begin{array}{c}k_{t} / k_{n} \\
(-)\end{array}$ & $\begin{array}{c}\tan (\varphi) \\
(-)\end{array}$ & $\begin{array}{c}D_{\min } \\
(\mu \mathrm{m})\end{array}$ & $\begin{array}{c}D_{\max } \\
(\mu \mathrm{m})\end{array}$ & $\begin{array}{c}\gamma \\
(\mathrm{N} / \mathrm{m})\end{array}$ & $\begin{array}{c}\theta \\
\left({ }^{\circ}\right)\end{array}$ \\
\hline 10 & 1 & 0.5 & 21 & 25 & 0.073 & 10 \\
\hline
\end{tabular}

The DEM model finally provides a straightforward access to micro-quantities related to both the liquid and solid phases, in addition to stresses and strains. The solid phase for instance can be characterized in terms of an average contact number $z_{c}$ :

$$
z_{c}=\frac{2 N_{c}-N_{1}}{N_{p}-N_{1}-N_{0}}
$$

with $N_{c}$ the total number of contacts, $N_{0}$ or $N_{1}$ the number of excluded rattlers, i.e. DE's with zero or only one contact, and $N_{p}$ the total number of DE's. 
Another useful solid phase characteristic is the contact fabric tensor $\boldsymbol{F}$ that depends on the contact orientation $\vec{n}$ of all contacts $c$ :

$$
\boldsymbol{F}=\frac{1}{N_{c}} \sum_{c} \vec{n} \otimes \vec{n}
$$

which leads to a measure of the contact anisotropy, $a_{c}$, through the deviatoric part of $\boldsymbol{F}$ :

$$
a_{c}=\sqrt{\frac{3}{2}}\left\|\boldsymbol{F}-\frac{1}{3} \operatorname{tr}(\boldsymbol{F}) \boldsymbol{\delta}\right\|=\sqrt{\frac{3}{2}}\left\|\boldsymbol{F}-\frac{1}{3} \boldsymbol{\delta}\right\|
$$

\section{$2.3 \quad$ Packing generation procedure}

All simulations considered herein apply to either dense or loose numerical packings consisting of 20,000 spherical particles confined within a rectangular parallelepiped. Classically, dense or loose initially isotropic packings are obtained through isotropic compression of an initial gas-like cloud of randomly located particles, until some desired confining pressure is reached, and using different interparticle friction coefficients during the process. Dense packings are achieved using a very low friction coefficient $\mu=\tan \left(0.5^{\circ}\right)$, allowing for optimal particle re-organization during the isotropic compression. On the other hand, the generation of loose packings involves the same friction coefficient that will eventually be used for the subsequent loading paths, i.e. $\mu=0.5 \approx \tan \left(26.6^{\circ}\right)$. Also, the evolution of loose packings during the initial isotropic compression should be as quasi-static as possible for the loosest state, i.e. purely contractant during shearing, to be eventually reached. To do so, using a reasonably high loading rate for computational cost reasons, numerical damping with a high (0.6) damping coefficient [26] is also used during this stage. Later on, during all subsequent loadings, a negligible amount of numerical damping (0.05 as damping coefficient) is used, while quasi-staticity is always checked against a very low level of unbalanced force ratio [26] (1\% or below) or kinetic over elastic energy ratio (1\%o or less).

With regard to wet granular materials, great care is taken to obtain wet packings that are comparable to dry packings so that any effective stress discussions can be pursued in an objective manner. Indeed, the behavior of sheared dry granular materials depends on the mean contact stress $p^{\text {cont }}$ and packing properties such as porosity $n$ and average contact number $z_{c}$. By definition, using an effective stress defined as $\boldsymbol{\sigma}^{\prime}=\boldsymbol{\sigma}^{\text {cont }}$ is expected to lead to the same dependencies for wet granular materials. However, it has been observed during wet samples preparation that the final packing properties are naturally affected by the presence of capillary forces, with much looser states in terms of $n$, or somewhat $z_{c}$, reached in wet than in dry conditions, for a given $p^{\text {cont }}$. These observations just correspond to experimental procedures such as moist tamping to obtain looser soil samples, but would here constitute a bias in the comparison between wet and dry results in an effective stress framework. Thus, capillary interactions are disregarded at the start of wet samples generation and are introduced only once the packing reaches the desired confining pressure. As a 
result, the influence of capillary forces on initial packing states is greatly minimized, leading to $\left(n, z_{c}, p^{\text {cont }}\right)$ states being as close as possible between dry and wet packings (Fig. 2), thus ensuring a non-biased comparison of wet and dry conditions.
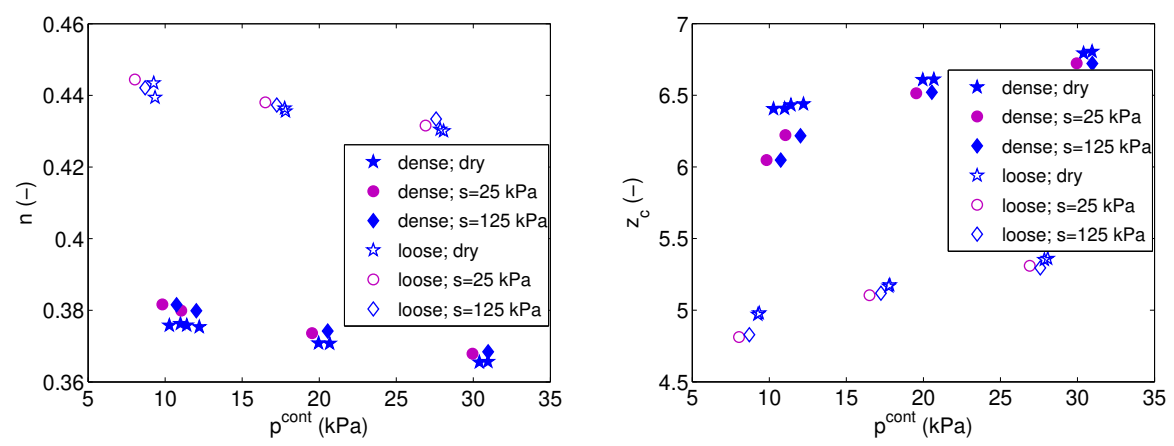

Figure 2: Initial microstructures of comparable samples to be tested in dry or wet conditions (for two suction values): porosity (left) and coordination number (right)

\section{DEM results sensitivity and constitutive bi- furcations}

As a prelude to the constitutive comparisons of wet and dry behaviors in Sections 4 and 5, the precision of the dry numerical simulation results is first assessed. The exercise consists of checking whether different numerical packings of the same type, either dense or loose, can be generated with minimal variations in macroscopic properties $\left(n, z_{c}\right)$ even though they involve different individual particles (Fig. 2). Also, for the same values of $n$ and $z_{c}$, it will be clear in the next sections that the results are not affected by the consideration of different individual particles as long as constitutive bifurcations are avoided.

Indeed, the non-associativity of granular materials leads to a second possible reason for numerical results dispersion through bifurcated behaviors when the loading path is not controllable [28, 29], or, equivalently, does correspond to a potentially unstable direction showing a negative second order work $[30,31,32]$.

For further discussion, the same triaxial compression is repeated three times: a classical mixed loading path $\left(d \varepsilon_{1}>0 ; d \Sigma_{2}=d \Sigma_{3}=0\right)$ is imposed on dense or loose packings during three runs of the same simulation. Runs \#2 and \#3 consider the exact same individual particles obtained after one unique run of the sample generation procedure; whereas run \#1 makes use of another - either dense or loose - packing obtained after another run of the generation procedure. Also, all numerical simulations have been executed in parallel, leading to different round-off errors among the runs. 

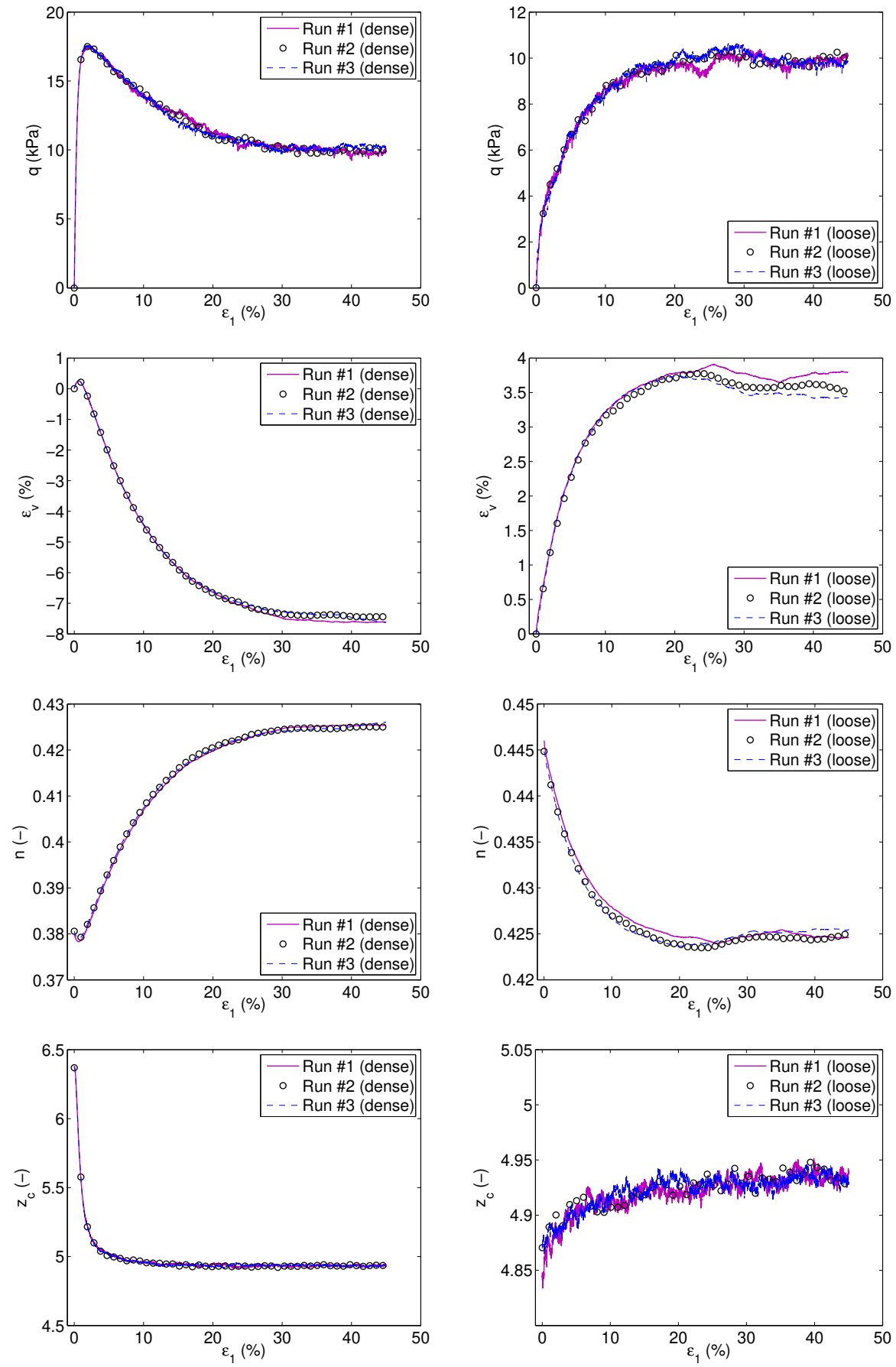

Figure 3: Repeatability of a dry classical triaxial compression with $10 \mathrm{kPa}$ confining pressure on dense (left) and loose (right) packings 
First of all, the comparison of the results in Fig. 3 further validates the robustness of the sample generation procedure that was used to obtain comparable dense or loose packings. As expected, only a minimal discrepancy in terms of initial $\left(n, z_{c}\right)$ is observed between runs \#1 and \#2-3, in the loose case. Also, all results eventually point to a critical state with a common final stress-porosity state for both packings [33], complemented by final common values for microquantities $a_{c}$ (not included in Fig. 3) and $z_{c}$ [34]. However, it is noted that the numerical results, although very close to each other, are not strictly identical even when initially considering the exact same individual particles with runs \#2-3.

As for the dense case, slight discrepancies are observed in the post-peak regime, which is clearly related to constitutive bifurcations. As a matter of fact, triaxial compression loading paths on dense packings are stable, i.e. controllable, until peak stress and potentially unstable beyond [31]. The post-peak dispersion of the dense results is nevertheless lower than what may be observed from lab experiments. Indeed, the numerical model examined herein is a granular system just large enough to represent a material REV, thus strain localization and field heterogeneity are here absent, whereas these would magnify the dispersion of dense experimental results.

A greater, though still limited, dispersion in results e.g. with regard to volumetric behavior is observed for the loose case. As the plastic limit threshold is reached around an axial logarithmic strain $\varepsilon_{1} \approx 25 \%$, the loading direction $d q=0$ is clearly a potentially unstable one so that discrepancies are expected between the runs. However, a close inspection of the results also reveals small discrepancies before plastic limit, while the loading direction is generally considered to be stable for loose packings [31]. The deviation between the different runs is actually accompanied by rugged strain-stress trends which are indicative of local buckling failure of force chains and metastable regions, causing stress release in a stick-slip mechanism $[35,36,37,34]$ also observed in the lab on loose ideal discrete systems (glass bead samples) [38]. While the average $q\left(\varepsilon_{1}\right)$ envelope monotonically increases toward the plastic limit, these sharp temporary stress variations $d q<0$ produce a negative second order work $d^{2} w=d q d \varepsilon_{1}$, contrary to the average loading direction, $d q>0$.

Bifurcated behaviors in relationship with stick-slip events are actually more prominent along other loading paths than the classical triaxial compression just considered in Fig. 3. Indeed, a dispersion in stress response clearly appears before the plastic limit when applying a given strain loading path (Fig. 4) twice to the exact same dry loose packing, considering two parallel runs of the same simulation. Comparing the two runs, a stress discrepancy is detected from an early axial strain $\varepsilon_{1} \approx 1.2 \%$. This strain corresponds to a stress ratio $\eta \approx 0.4-$ while the plastic limit is reached for $\eta_{\max } \approx 0.75$ - and to the first significant stick-slip event for this loose material (Fig. 3 and 4). Repeated stick slips then exacerbate the stress discrepancy between the two runs, in terms of individual stress components only. Indeed, the macro-scale stress ratio $\eta$ is virtually unaffected, such as micro-scale contact anisotropy $a_{c}$. In connection with the greater mean stress during the second run, a slightly greater average contact number 

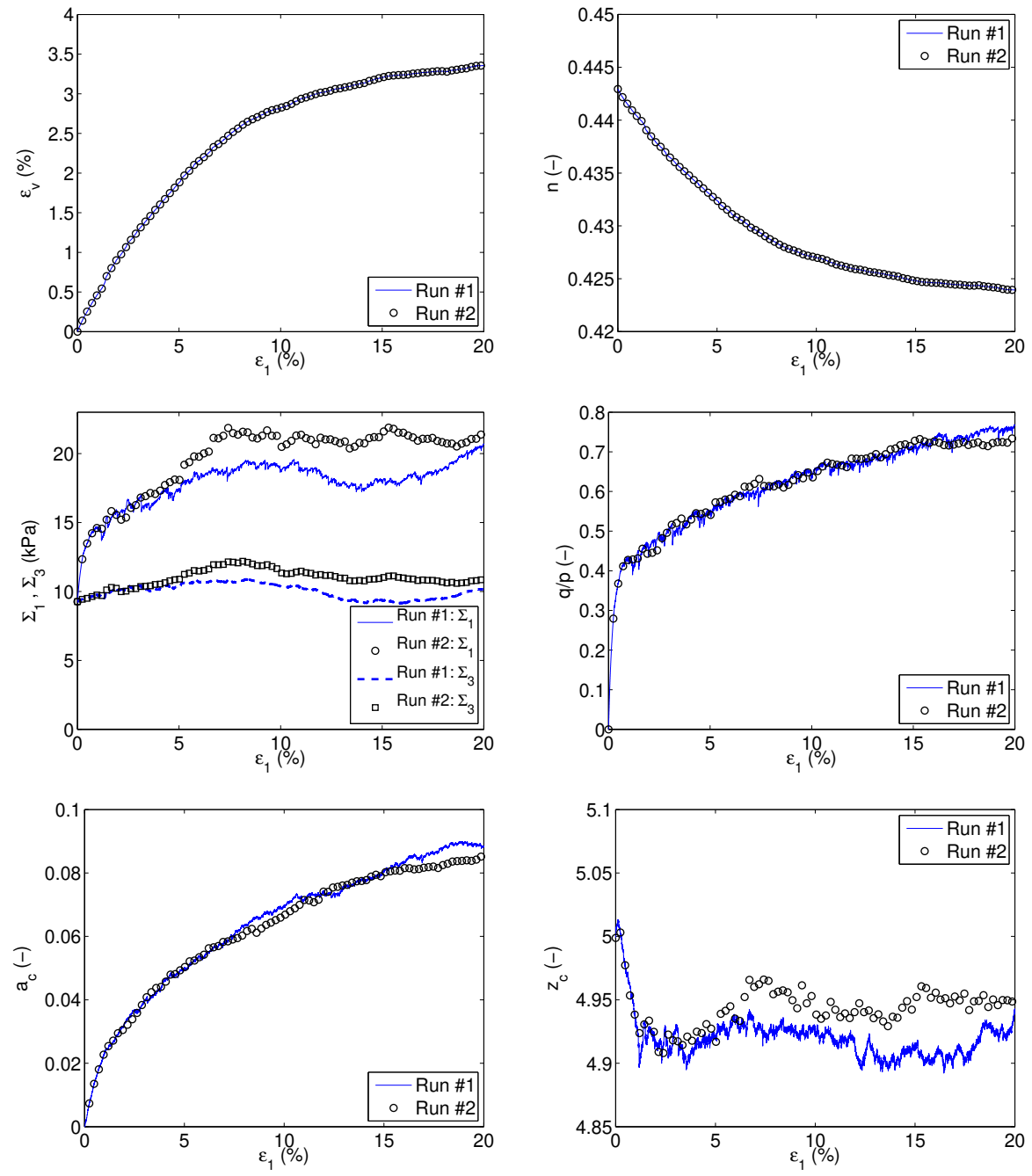

Figure 4: Repeatability of a strain controlled loading path (with initial confining pressure $p=9.3 \mathrm{kPa}$, and imposed strains in the top-left figure) for a loose packing 
$z_{c}$ is also measured for this run.

The non-exact repeatability of the behavior during the present strain control test also implies a non-exact equivalence between strain control and e.g. mixed control tests on loose packing. As an illustration, it is to note that the strain control test (Fig. 4) just imposes a strain path previously measured during the classical, mixed control, triaxial compression (Fig. 3). However, a $\pm 10-$ $15 \%$ variation in the lateral stress is observed during the strain control test, at variance with the behavior during the mixed control test.

As a final remark, we note that the comparison of strain control and mixed control tests could theoretically be also affected by the incrementally non-linear behavior of granular materials, together with an absence of servo-control and associated oscillations in the strain control test, as discussed in depth in [39]. However, it was also shown in [39] that this issue has a limited influence when the servo-control is precise enough, such as done here.

\section{Effective stress for failure description}

\subsection{Contact stress as an effective stress for failure descrip- tion}

The numerical model is now applied to a series of 28 triaxial tests (Table 2) in dry and wet conditions, in order to precisely confirm the effective nature of $\sigma^{\text {cont }}$ with reference to a unique failure description in terms of stress limit states. The first half of the test series considers wet conditions, with fourteen suctioncontrolled tests being conducted at different suction levels, packing densities and confining pressure values. The second half of the series considers as many dry triaxial tests, seeking dry conditions that would allow a meaningful comparison of the stress limit states with wet conditions.

As a starting point, it was successfully verified that the solid phase microstructure in terms of porosity and coordination number as depicted in the previous Fig. 2 was comparable between the dry and wet specimens, thanks to the robustness of the sample generation procedure described back in Section 2.3 .

Also, the imposed constant lateral stress, $\Sigma_{3}$, of any dry test is chosen as the contact stress lateral component, $\sigma_{3}^{\text {cont }}$, which is measured at failure during the corresponding wet test using Eq. (2), (4) or (6). It is noted that such micro-mechanical equations give significantly different insights than the classical equation $\boldsymbol{\sigma}^{\prime}=\boldsymbol{\Sigma}+s S_{r} \boldsymbol{\delta}$ inspired by Bishop [2], as further discussed in [22, 5].

As a result of these test choices, some dry tests consider virtually identical microstructures and lateral pressure. These superfluous tests are still included to check once more the reproducibility of the numerical results, now in terms of shear strength.

Then, it is first of all verified that wet compression tests show an accurate coincidence between the occurrences of total stress limit states and contact stress limit states. During classical triaxial loadings in both dry and wet conditions, 
Table 2: Comparable dry and wet triaxial compression tests chosen for failure analyses. Reported saturation values correspond to failure (limit stress) states

\begin{tabular}{|c|c|c|c|c|}
\hline & $\Sigma_{3}(\mathrm{kPa})$ & $\begin{array}{l}\text { Wet } \\
s(\mathrm{kPa})\end{array}$ & $S_{r}(\%)$ & $\begin{array}{c}\text { Dry } \\
\Sigma_{3}(\mathrm{kPa}) \\
\end{array}$ \\
\hline \multirow{8}{*}{$\begin{array}{l}\text { Dense } \\
\text { packing }\end{array}$} & 1 & 25 & 7.5 & 10.3 \\
\hline & 2 & " & 7.6 & 11.4 \\
\hline & 10 & " & 8.3 & 20.0 \\
\hline & 20 & $"$ & 8.9 & 30.4 \\
\hline & 1 & 125 & 0.81 & 11.0 \\
\hline & 2 & $"$ & 0.83 & 12.2 \\
\hline & 10 & $"$ & 0.89 & 20.7 \\
\hline & 20 & $"$ & 0.94 & 30.9 \\
\hline \multirow{6}{*}{$\begin{array}{l}\text { Loose } \\
\text { packing }\end{array}$} & 2 & 25 & 5.0 & $\begin{array}{l}9.3 \\
\end{array}$ \\
\hline & 10 & " & 5.6 & 17.8 \\
\hline & 20 & $"$ & 5.9 & 28.1 \\
\hline & 2 & 125 & 0.51 & 9.3 \\
\hline & 10 & $"$ & 0.56 & 17.8 \\
\hline & 20 & $"$ & 0.58 & 27.8 \\
\hline
\end{tabular}

total stress limit states may be indistinctly defined from the occurrence of a maximum deviatoric total stress $q_{\max }$, or a maximum total stress ratio $\eta_{\max }$. On the other hand, contact stress limit states during wet compression tests are defined from the occurrence of a maximum contact stress ratio $\eta_{\max }^{\text {cont }}$ only, since the lateral contact stress is not controlled as a loading parameter during such tests and may evolve.

Whether $\boldsymbol{\Sigma}$ reaches its limit state at the same time as $\boldsymbol{\sigma}^{\text {cont }}$ does and viceversa, is verified by measuring the two following ratios for each test: $\eta^{\text {cont }}(\eta=$ $\left.\eta_{\max }\right) / \eta_{\max }^{\text {cont }}$ and $\eta\left(\eta^{\text {cont }}=\eta_{\max }^{\text {cont }}\right) / \eta_{\max }$. An exact coincidence of the two limit stress states would lead to both ratios being equal to 1 . During the numerical simulations, this ideal situation is very closely approximated for all tests (Fig. 5), justifying to consider $\sigma^{\text {cont }}$ limit states to interpret total stress limit states in wet conditions.

Finally, the comparison is made between the contact stress limit states observed in dry and in wet conditions as shown in Fig. 6. From this comparison and considering for instance an average value of $20 \mathrm{kPa}$ for the lateral stress, it is observed that the maximum axial contact stress in wet conditions differs from the dry one by approximately $7 \%$ maximum, in the worst case of the dense packing tested under a $25 \mathrm{kPa}$ suction. For a $125 \mathrm{kPa}$ suction or in the loose packing, the wet vs. dry differences in strength are even smaller. Similar comparisons considering the total stress or the above-mentioned Bishop's stress $\boldsymbol{\sigma}^{B i s h}=\boldsymbol{\Sigma}+s S_{r} \boldsymbol{\delta}$ would lead to much larger discrepancies between dry and wet conditions: around $40 \%$ for the dense packing and $20 \%$ for the loose one.

As such, it appears that $\sigma^{\text {cont }}$, contrary to $\boldsymbol{\Sigma}$ or $\boldsymbol{\sigma}^{\boldsymbol{B i s h}}$, may indeed serve as an adequate effective stress for failure description since there is a very close 

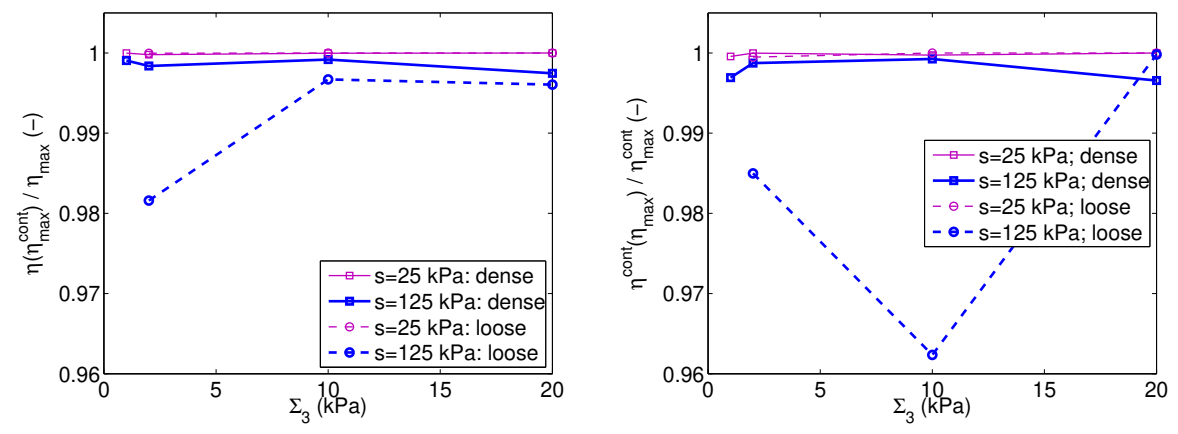

Figure 5: Coincidence of limit stress states for $\boldsymbol{\Sigma}$ and $\boldsymbol{\sigma}^{\text {cont }}$ in wet conditions
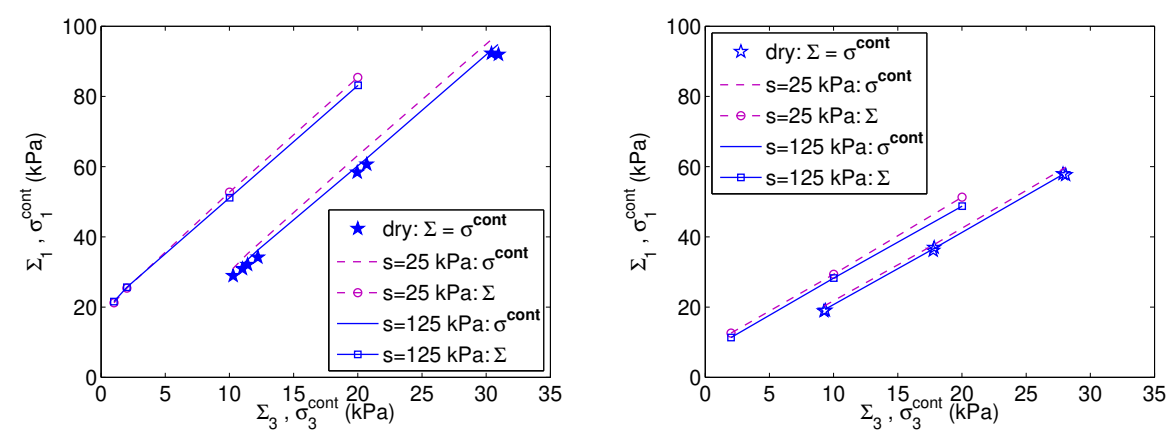

Figure 6: Limit stress states in dry and wet conditions. For dense (left) and loose (right) packings 
agreement between contact stress limit states in wet conditions and contact stress limit states in dry conditions, for a given solid packing.

\subsection{Role of the solid phase microstructure}

As expected, the possibility for wet and dry conditions to be compared at failure, using $\sigma^{\text {cont }}$ as an effective stress, still requires special conditions for what concerns the solid phase microstructure in terms of $\left(n, z_{c}\right)$. Indeed, care was previously taken to obtain dry and wet samples showing as close as possible initial microstructures (Fig. 2), enabling limit stress states to be unified (Fig. 6).

On the other hand, two extra wet tests are now considered, being performed on two wet samples denoted "ws1" and "ws2" having distinct solid phase microstructures with respect to the reference dry tests (Fig. 7). In contrast to
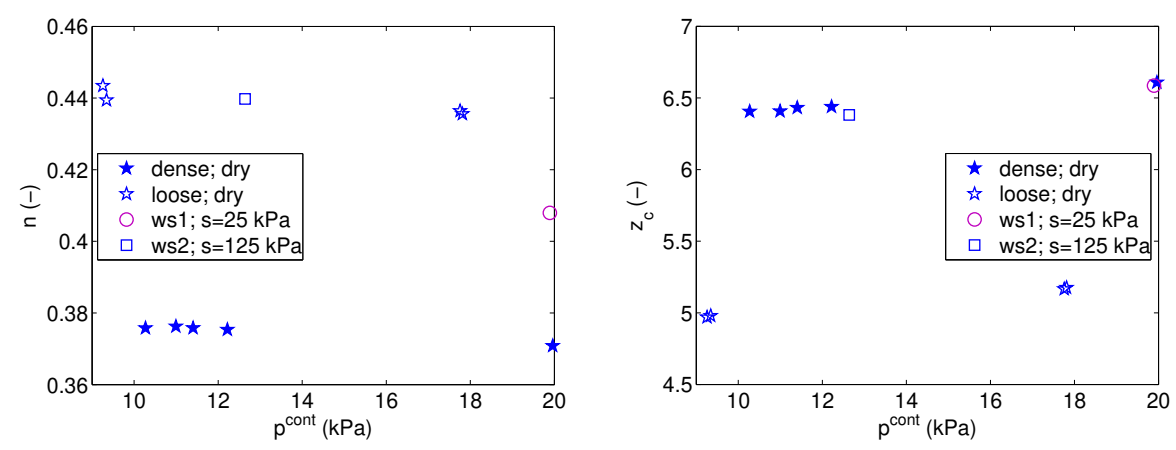

Figure 7: Initial microstructures of non-comparable samples tested in dry or wet conditions: porosity (left) and coordination number (right)

the generation procedure presented back in Section 2.3 and used in the above, these two samples have been generated applying unsaturated conditions from the very start of the isotropic compression used for packing preparation. Also, for both samples ws1 and ws2, the contact friction coefficient during the compression was set to $\tan \left(0.5^{\circ}\right)$. Once generated, the two samples ws1 and ws 2 show comparable coordination numbers as previous so-called dense packings, but different porosities, see Fig. 7. Sample ws1, prepared and tested under 25 $\mathrm{kPa}$ suction and $10 \mathrm{kPa}$ confining pressure, shows an intermediate porosity between dense and loose dry packings. On the other hand, sample ws2, prepared and tested under $125 \mathrm{kPa}$ suction and $3 \mathrm{kPa}$ confining pressure, shows in fact the same porosity as loose dry packings, although having a coordination number comparable to dense dry packing.

Once tested under unsaturated triaxial compression, these two samples show contact stress limit states that cannot be precisely related to the dry limit states of either the dense or the loose packings as illustrated in Fig. 8. The observed discrepancy prompts the need to have a complete characterization of the solid phase microstructure in terms of both $n$ and $z_{c}$, and an adequate generation 
procedure.

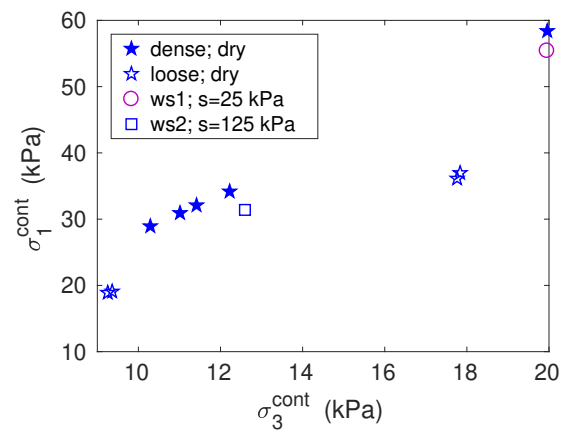

Figure 8: Limit contact stress states in dry and wet conditions for noncomparable solid phases

\section{Effective stress for constitutive behavior}

\subsection{Investigation method}

A description of the pre-failure stress-strain behavior of dry granular materials involves constitutive equations $\mathcal{F}$ or $\mathcal{G}$ that directly relate the strain and stress loading paths together, i.e. $[\varepsilon(\tau) ;-\infty<\tau \leqslant t]$ with $[\boldsymbol{\Sigma}(\tau) ;-\infty<\tau \leqslant t]$, in the absence of constitutive bifurcations:

$$
\varepsilon(t)=\mathcal{F}([\boldsymbol{\Sigma}(\tau) ;-\infty<\tau \leqslant t]) \Leftrightarrow \boldsymbol{\Sigma}(t)=\mathcal{G}([\varepsilon(\tau) ;-\infty<\tau \leqslant t])
$$

Obviously, dry granular materials satisfy to the equality: $\boldsymbol{\Sigma}=\boldsymbol{\sigma}^{\boldsymbol{c o n t}}$. We also note that the constitutive functionals $\mathcal{F}$ and $\mathcal{G}$ are expressed differently for a dense or loose granular skeleton, and that such a functional formalism (14) may be replaced with an incremental formalism for practical purposes.

An effective stress variable $\boldsymbol{\sigma}^{\prime}$ for wet granular materials obeying to the effective stress principle in its strongest form (i.e. including constitutive behavior) would enter the same equations to describe the strains of wet soils, similarly to the saturated case and Biot's equations [6]:

$$
\varepsilon(t)=\mathcal{F}\left(\left[\boldsymbol{\sigma}^{\prime}(\tau) ;-\infty<\tau \leqslant t\right]\right) \Leftrightarrow \boldsymbol{\sigma}^{\prime}(t)=\mathcal{G}([\varepsilon(\tau) ;-\infty<\tau \leqslant t])
$$

As for dry or saturated conditions, the strains under unsaturated conditions still originate from the solid skeleton of the granular material [15], arising from grain relative displacements under the actions of both capillary and contact forces. Because the contact-scale constitutive relations between contact forces and particles relative displacement are identical in dry and wet conditions, it is reasonable to investigate whether the same macro-scale constitutive relations 
$\mathcal{F}, \mathcal{G}$ also relate the contact stress $\sigma^{\text {cont }}$ to the strains $\varepsilon$ in wet conditions, i.e. whether $\sigma^{\text {cont }}$ is a complete stress-strength-strain effective variable:

$$
\varepsilon(t) \stackrel{?}{=} \mathcal{F}\left(\left[\sigma^{\text {cont }}(\tau) ;-\infty<\tau \leqslant t\right]\right) \Leftrightarrow \sigma^{\text {cont }}(t) \stackrel{?}{=} \mathcal{G}([\varepsilon(\tau) ;-\infty<\tau \leqslant t])
$$

The validity of Eq. (16) involves the existence of $\mathcal{G}$ that is herein investigated by comparing contact stress paths in dry and wet conditions for a given strain path. The checking procedure involves two sets of DEM simulations as follows.

1) First, a triaxial compression test is performed on either dense or loose samples under wet condition by imposing a classical mixed control $\left(d \varepsilon_{1}>0 ; d \Sigma_{2}=\right.$ $d \Sigma_{3}=0$ ) load, while measuring the resulting contact stresses $\boldsymbol{\sigma}^{\text {cont }}$ together with the strains $\varepsilon$.

2) The strain path measured in 1) is then applied as an axisymmetric strain loading path $\left(d \varepsilon_{1} ; d \varepsilon_{2}=d \varepsilon_{3}\right)$ to a similar dense or loose packing, but in dry conditions. Essentially, in this dry simulation, strains are directly imposed to follow the same strain path as in the wet simulation in 1), and the resulting contact i.e. total stresses are measured.

Thus, referring to the above, if the same constitutive relations hold between $\varepsilon$ and $\sigma^{\text {cont }}$, the contact stress path observed in the dry (strain-control) simulation in 2) should correspond to the one in the wet (mixed-control) simulation in 1) for any saturation, provided that constitutive bifurcations are avoided. It is recalled that the servo-control used in the mixed-control test is precise enough so that the comparison should not be influenced by the control mode alone, in spite of the incremental non-linearity of the behavior [39].

As a proof of concept, the proposed procedure is first tested in dry conditions on both dense and loose samples. A dense and a loose sample are each compressed under the two loading control modes previously mentioned so that strain and stress paths, including micro-scale quantities, are measured as shown in Fig. 9. In order to improve the clarity of Fig. 9, two slightly different lateral stresses, both close to $10 \mathrm{kPa}$, are imposed to the dense and the loose samples during the mixed control loading path.

Consistent with the existence of constitutive relations $\mathcal{F}, \mathcal{G}$, a unique behavior is displayed during the two tests initially as seen in Fig. 9. Then, individual stress discrepancies occur for both samples due to the constitutive bifurcations discussed back in Section 3. Basically, differences set in from an axial strain $\varepsilon_{1} \approx 1 \%$ which is close to the peak stress of the dense sample, or to the first significant stick-slip event for the loose sample. From this point onwards, the lateral stress deviates from a constant value during the strain controlled test. The average contact numbers of dense or loose samples are also affected together with the mean stress. However, a virtually unique behavior in terms of $q / p$ and $a_{c}$ is observed until $25 \%$ axial strain, irrespective of the control mode.

This proof of concept exercise clarifies the situation when constitutive bifurcations may affect a comparison between mixed control wet tests and strain control dry tests, even though $\sigma^{\text {cont }}$ would correspond to an effective stress for wet granular materials according to Eq. (16). 

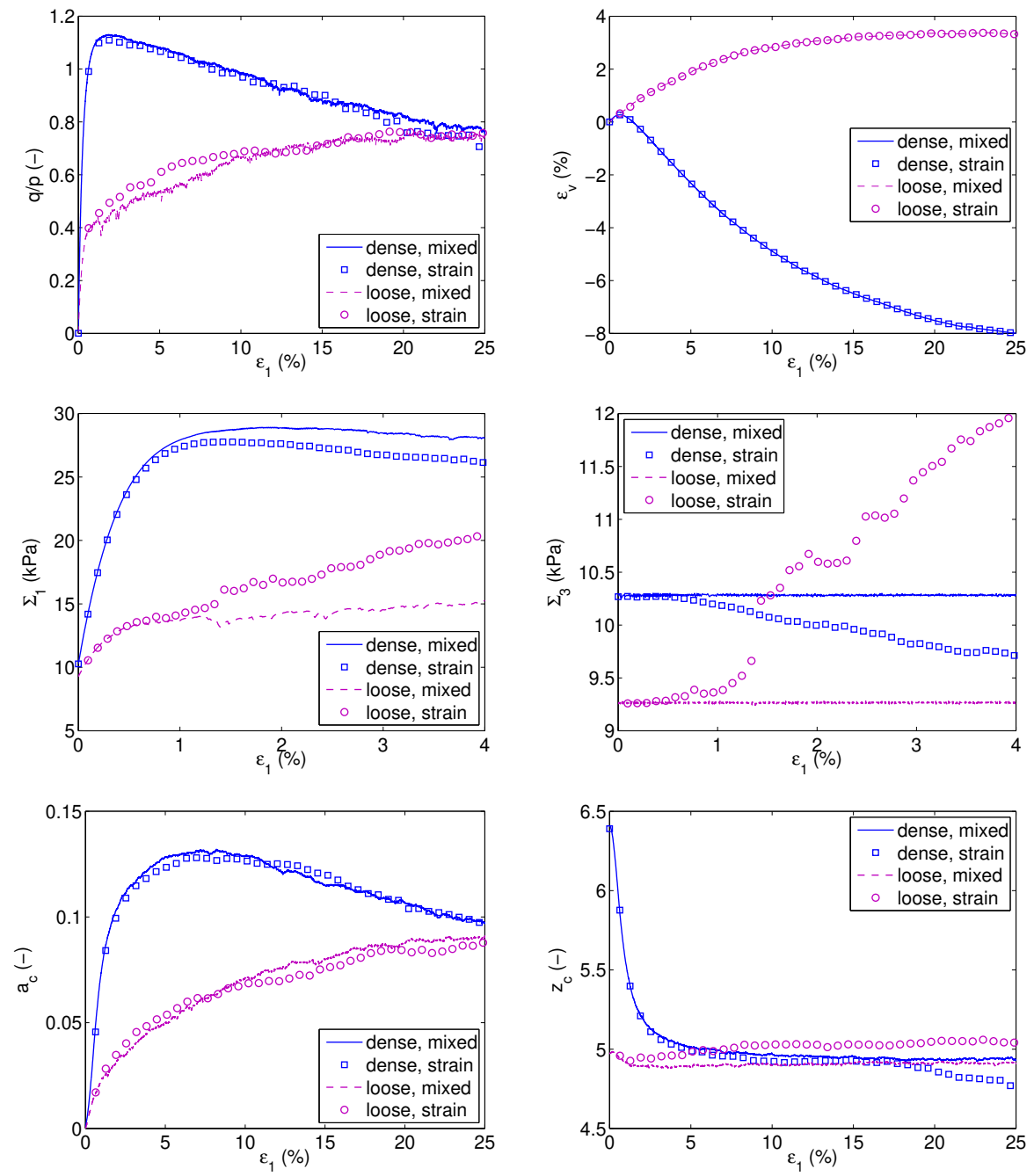

Figure 9: Loose and dense behaviors during dry axisymmetric compressions with different control modes (mixed control or strain control) 


\subsection{Quasi-static behavior}

Dry-wet comparisons are now performed considering two pairs (A, B) of wet mixed-control and dry strain-control tests, for each type of packing (dense or loose). Within each test pair (A, B), and for each packing, the dry and wet tests show comparable initial microstructures and contact stress. Additional dry tests (A', B') are also considered and compared with wet tests (A, B) for the dense packing in the case only total stress are comparable; see Table 3.

Table 3: Considered lateral stress and suction values for constitutive comparison of wet mixed-control and dry strain-control tests. The two dry-wet test pairs A, B show comparable initial contact stress and packing. Dry tests A' and B' serve an additional comparison in terms of total stress only with wet tests A, B (for the dense packing)

\begin{tabular}{c|c|c|c|c|c|c|} 
& \multicolumn{2}{|c|}{ Imposed $\Sigma_{3} ; s(\mathrm{kPa})$} & \multicolumn{4}{|c|}{ Initial $\Sigma_{3}(\mathrm{kPa})$} \\
& Wet A & Wet B & Dry A & Dry B & Dry A' & Dry B' \\
\hline Dense sample & $1 ; 125$ & $10 ; 25$ & 10.7 & 19.5 & 1 & 10 \\
\hline Loose sample & $2 ; 125$ & $10 ; 25$ & 8.7 & 16.5 & - & - \\
\hline
\end{tabular}

Upon comparisons of the dense packings, both A and B test pairs show very close contact stress behaviors when the same strain path is followed in dry and wet conditions, until contact stress peaks at an axial strain $\varepsilon_{1} \approx 1.5 \%$ for test pair $\mathrm{A}$, and $\varepsilon_{1} \approx 3 \%$ for pair $\mathrm{B}$ (Fig. 10). Within this range, the macroscale strain-contact stress agreement holds for individual stress components in addition to $\eta^{\text {cont }}$, and is complemented by close micro-scale trends for $a_{c}$ and $z_{c}$. This remarkable agreement shows the validity, within this range of the tests, of dry constitutive equations to describe wet conditions through $\sigma^{\text {cont }}$ and Eq. (16).

On the other hand, it would obviously not be possible to unify dry and wet constitutive behaviors considering total stress $\boldsymbol{\Sigma}$ instead of $\sigma^{\text {cont }}$. For illustration purposes, this is still attempted comparing the dry tests A' and B' to the wet tests $\mathrm{A}$ and $\mathrm{B}$ for this dense packing (Table 3). As expected, this leads to a much greater discrepancy for all the variables of interest (Fig. 11), illustrating how the dry constitutive functionals $\mathcal{F}, \mathcal{G}$ do not relate $\boldsymbol{\Sigma}$ to $\varepsilon$ in wet conditions.

Past the initial agreement between strain and contact stress paths in dry and wet conditions, greater discrepancies nevertheless set in upon loading of the dense samples (Fig. 10). The applied strain path makes the contact stress to eventually vanish in dry conditions, contrary to what was observed in wet conditions, after the contact stress ratios had previously deviated between the dry and wet tests. It is to note however that constitutive interpretations are more difficult in this post-stress peak range, as previously discussed in Sections 3 and 5.1.

With regard to the loose packing, contact stress-strain behaviors favorably compare between dry and wet conditions for what concerns the initial stiffnesses 

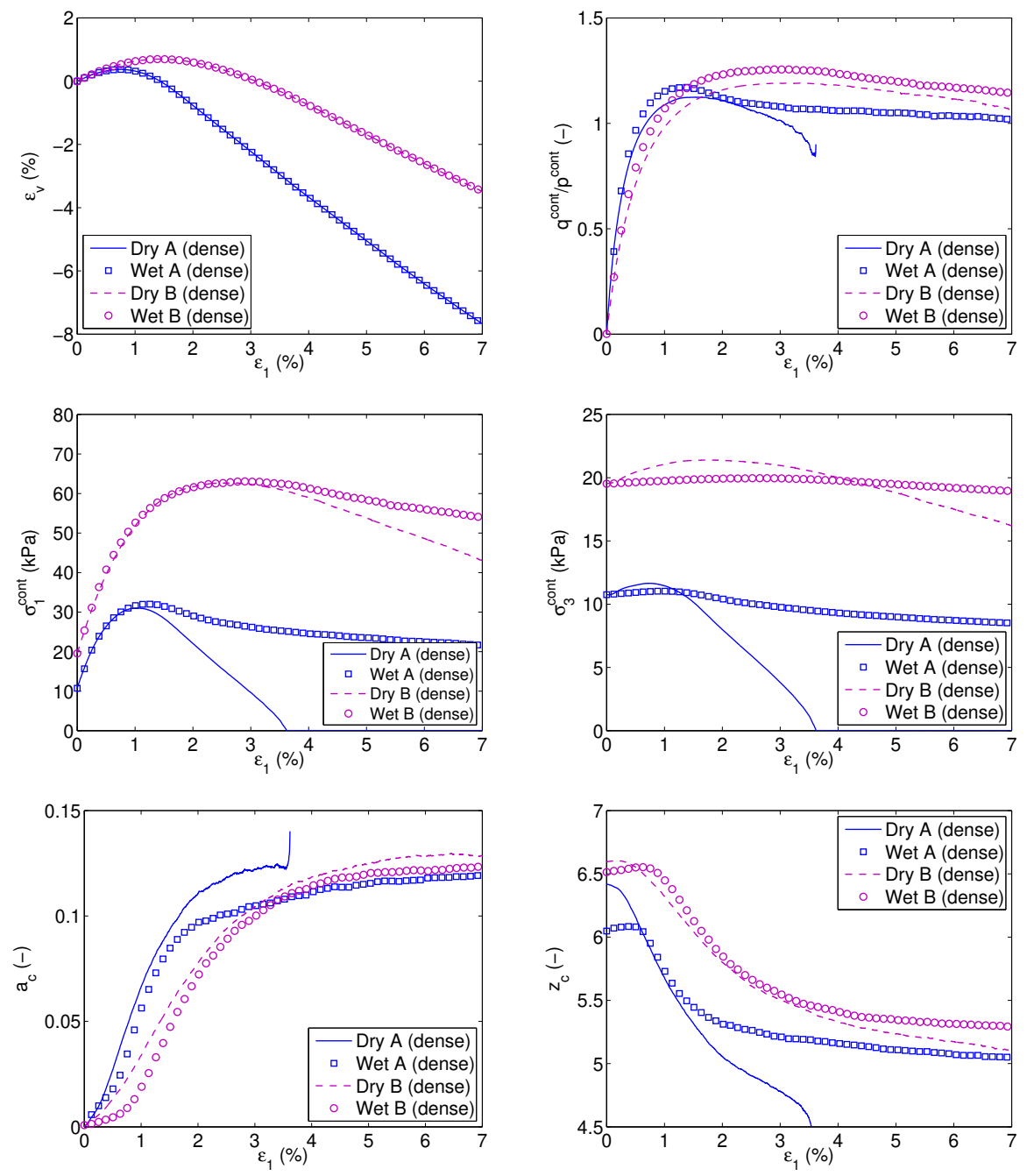

Figure 10: Contact stress interpretation of dry and wet dense constitutive behaviors. For "Dry A" test, meaningless $a_{c}, \eta^{\text {cont }}, z_{c}$ data are disregarded once contact stresses vanish, from $\varepsilon_{1} \approx 3.6 \%$ 

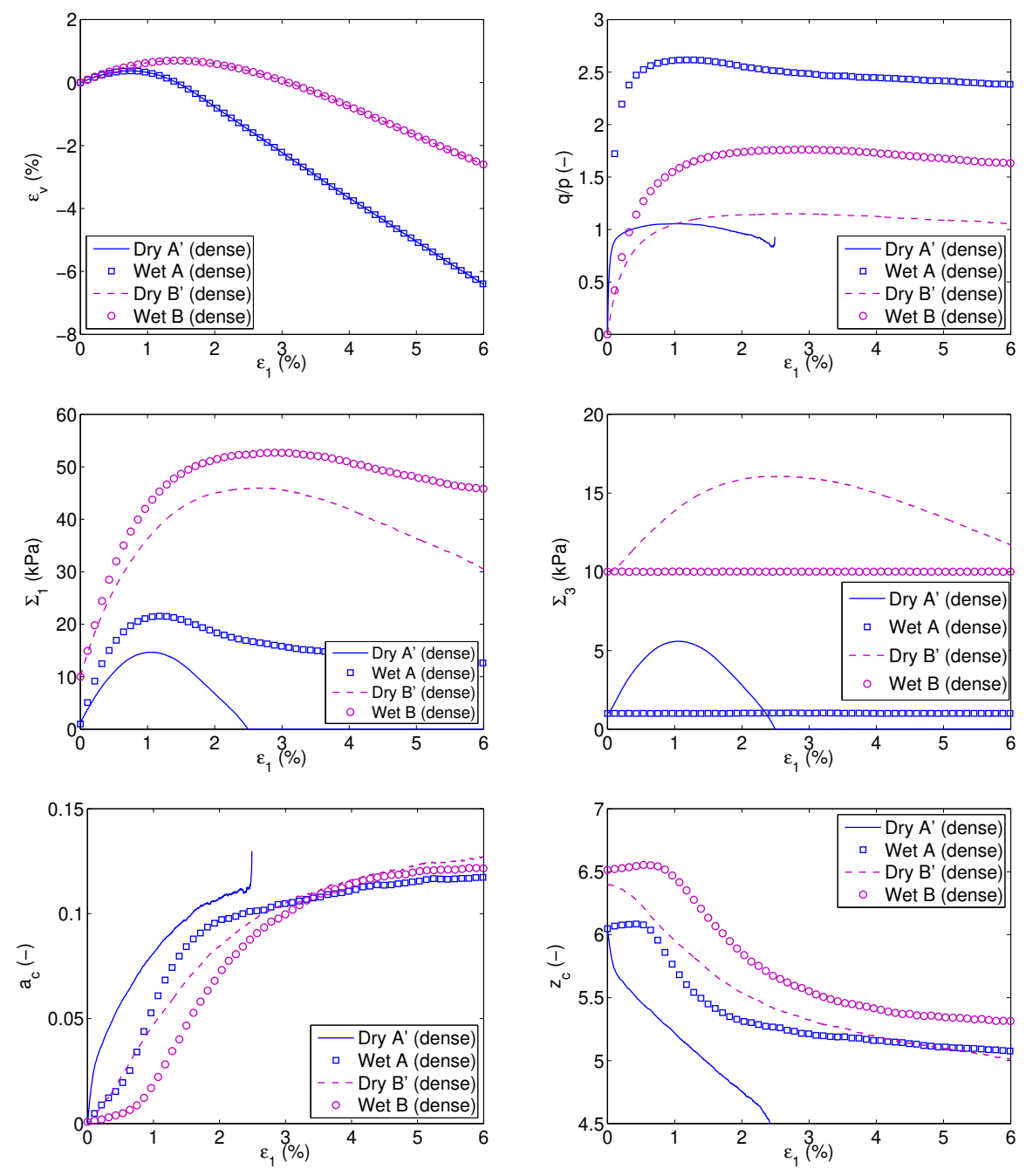

Figure 11: Total stress interpretation of dry and wet dense constitutive behaviors. For "Dry A'" test, meaningless $a_{c}, \eta, z_{c}$ data are disregarded once total stresses vanish, from $\varepsilon_{1} \approx 2.5 \%$ 
(Fig. 12), be it for individual principal contact stresses or the contact stress ratio. This initial uniqueness of the macro-scale contact stress-strain behavior also reflects at the micro-scale for both $a_{c}$ and $z_{c}$. Again, this means that the same constitutive functionals applied to $\sigma^{\text {cont }}$ describe the initial stiffnesses of dry and wet loose granular materials.

During further loading, discrepancies appear afterwards e.g. in $\eta^{\text {cont }}$, which clearly illustrates the dry loose constitutive functionals do not relate $\varepsilon$ with $\sigma^{\text {cont }}$ in wet conditions outside the very initial behavior range. In particular, maxima for $\eta^{\text {cont }}$ values significantly differ between dry and wet conditions even though it is to note that this maxima comparison does not relate to the stress-strength effective nature of $\sigma^{\text {cont }}$ previously discussed. Indeed, the strain-controlled path in dry conditions does not necessarily reach the plastic limit, just like an undrained triaxial compression on a saturated loose sample, i.e. a constant-volume compression, would not reach the corresponding MohrCoulomb criterion.

The extent of the validity range of $\boldsymbol{\sigma}^{\text {cont }}$ to serve as an effective stress arguably relates to the different micro-scale strain regimes identified for granular materials in [40, 41, 42]. As discussed therein, the rheological behavior of dense samples first involves a so-called quasi-static strain regime during which an increasing load is transmitted through a fixed contact network, without any creation of new contacts. At the end of this strain regime denoted 'I', some limit load will trigger a drastic change in the contact network whereby new contacts create, others being possibly lost, in order to sustain further load increase. On the heels of the previous strain regime I, this strain regime with drastic changes in contact topology is denoted by 'II'. As shown in [42], the extent of the quasistatic regime I is reduced for looser granular materials, dwindling to nothing in the case of the herein considered purely contractant loose sample. As such, the quasi-static strain regime can be approximately identified with the pre-peak, or the very initial (initial stiffness) phases of loading for dense or loose packings, respectively. Within this domain, the uniqueness in dry and wet conditions of contact stress-strain constitutive relationships is obviously established.

This micro-mechanical discussion somewhat relates to other fundamentally different approaches in $[8,18,43]$, which proposed that the elastic stiffnesses of unsaturated soils are adequately described by a single-valued effective stress which enters dry constitutive relations [8, 18], or pointed out the need for two distinct effective stress variables in elastic and elasto-plastic regimes [43]. Even though granular materials may lack the dichotomy between elastic and plastic strains [44, 45], making impossible any strict equivalence between the strain regime nature (I or II) and the elastic or elasto-plastic character of the behavior $[41,42,45]$, it could still be said that the quasi-static strain regime I obeying $\sigma^{\prime}=\sigma^{\text {cont }}$ is closer to elasticity since it shows no changes in contact network and less micro-scale sliding contacts than in the strain regime II [42], both ingredients for plasticity in granular materials. 

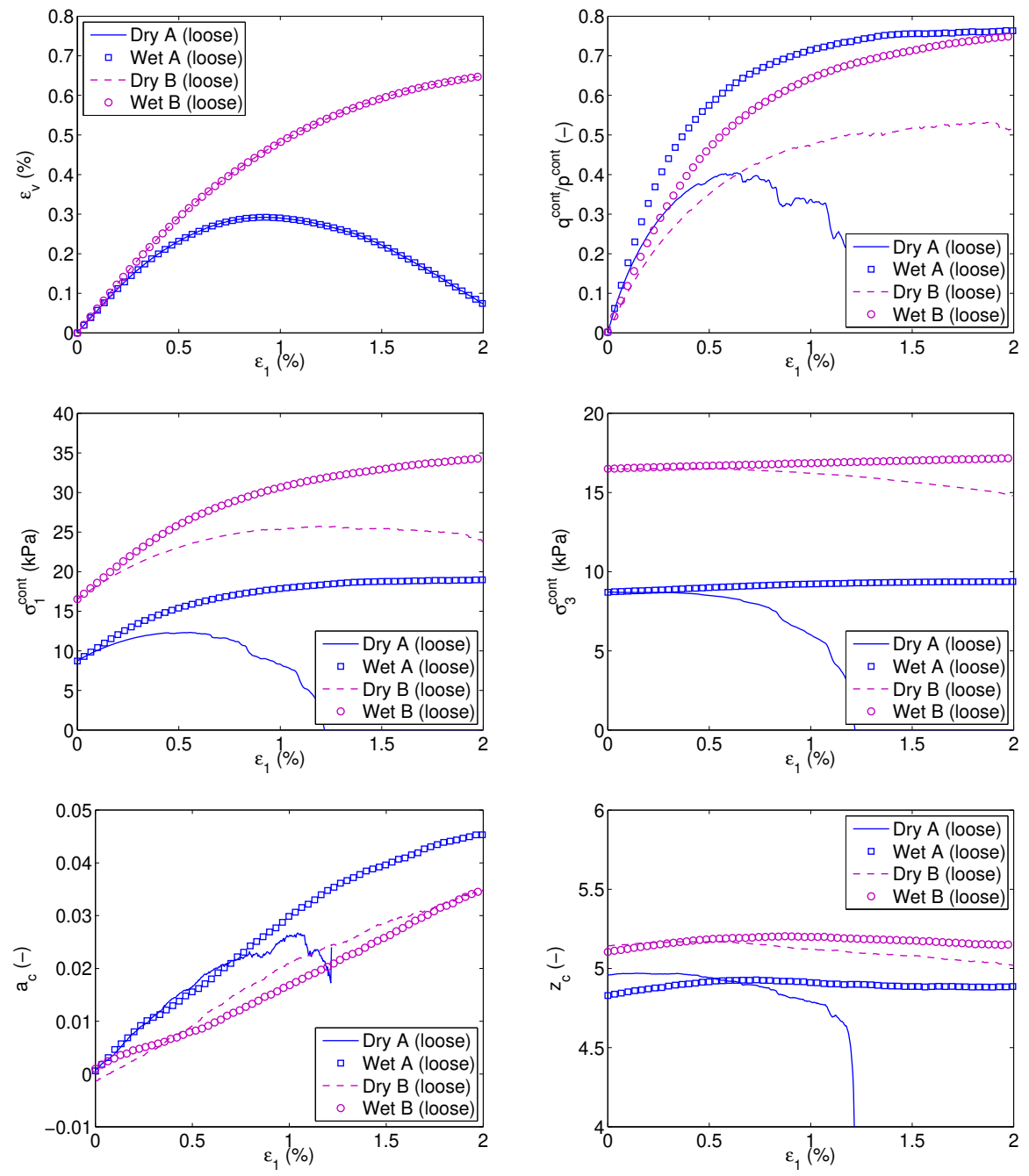

Figure 12: Contact stress interpretation of dry and wet loose constitutive behaviors. For "Dry A" test, meaningless $a_{c}, \eta^{\text {cont }}, z_{c}$ data are disregarded once contact stresses vanish, from $\varepsilon_{1} \approx 1.2 \%$ 


\subsection{Influence of intergranular friction}

The role of frictional sliding on impacting the effective nature of the contact stress is further illustrated by considering an extreme case of the DEM model similar to [46] where contact sliding is absent due to an 'infinite' friction coefficient for the contact interaction. This also corresponds to including an 'infinite' cohesion in the model since no threshold exists anymore for the tangential force, as long as the interaction exists with a normal overlap and a normal force. Brittle local ruptures nevertheless occur whenever the contact is lost during particle separation, leading the shear force to instantaneously disappear with some loss of elastic energy, which corresponds to a so-called acoustic emission [46].

This model is applied to the same type of loose packings that were previously considered, i.e. constructed with an initial local friction coefficient of 0.5 , before the frictional threshold is disregarded. First of all, it is noted that the change in contact law obviously affects the overall mechanical behavior as seen in Fig. 13. In contrast with the previous purely contractant behaviors of similar loose packings, the modified model now shows some dilation during classical dry triaxial compression. Also, a peak stress is now obtained, followed by a softening behavior.

Regarding the dry-wet comparison for a given strain path, an improved agreement between contact stress paths is actually obtained for the test pair B (see Table 3) in the absence of contact plastic sliding. Focusing on the loose packing which is the most sensitive to contact sliding in real frictional situations, it is observed in Fig. 13 that the contact stress dry-wet agreement extends well beyond the very initial behavior, now that the local plastic limit has been removed so that tangential forces are unbounded.

\subsection{Critical state line}

The critical state, which is reached after large shear strains and packing reorganizations, well beyond the quasi-static regime, is another instance of the failure of $\sigma^{\text {cont }}$ to represent an effective stress in wet conditions throughout the whole behavior. In both dry and wet conditions, unique stress-porosity states are finally obtained whatever the initial packings (with higher axial strains in the wet case than in the dry one), thus enabling one to define critical state lines (CSL) in a $n$ vs. $p^{\text {cont }}$ plot. The same CSL $n$ vs. $p^{\text {cont }}$ should exist for dry and wet granular soils if the contact stress governs in the same manner their ultimate plastic flow. However, Fig. 14 shows a clear discrepancy in the CSL obtained for the dry and wet triaxial tests presented back in Table 2. For the same final mean contact stress, wet granular soils show much looser critical states than the dry granular soils, serving as another evidence that the contact stress is to be an effective stress in a limited strain regime only.

The discrepancy in terms of $n$ vs. $p^{\text {cont }}$ adds to the expected discrepancy in terms of total stress and $n$ vs. $p$ CSL (Fig. 14) between dry and wet conditions. Such CSL differences in total stress have also been experimentally observed on silty clay [47], and relate to a greater dilatancy of wet granular materials 

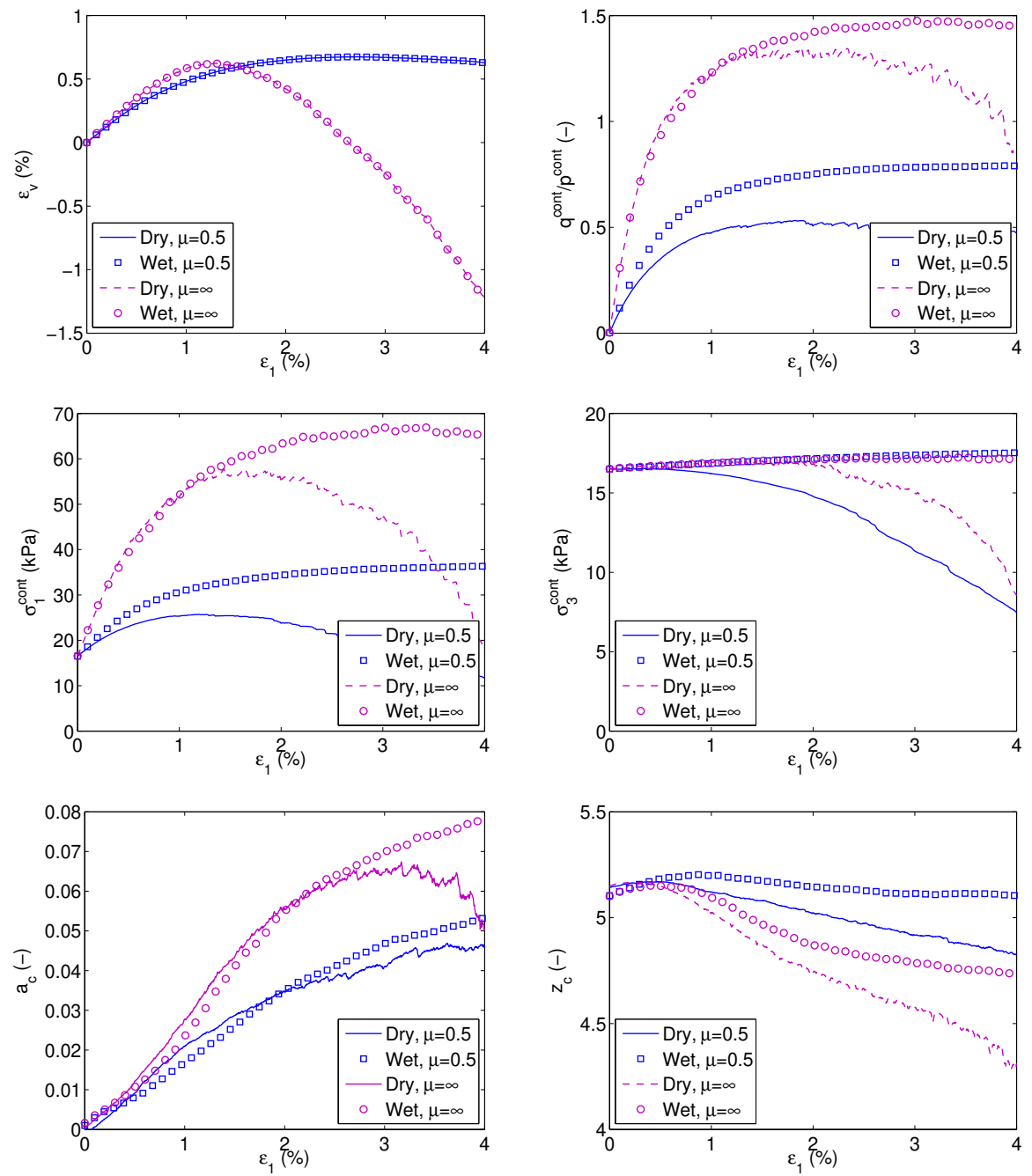

Figure 13: Influence of the interparticle friction coefficient $\mu=\tan (\varphi)$ on the contact stress effective nature for a loose packing, considering the dry-wet test pair B (see Table 3) 


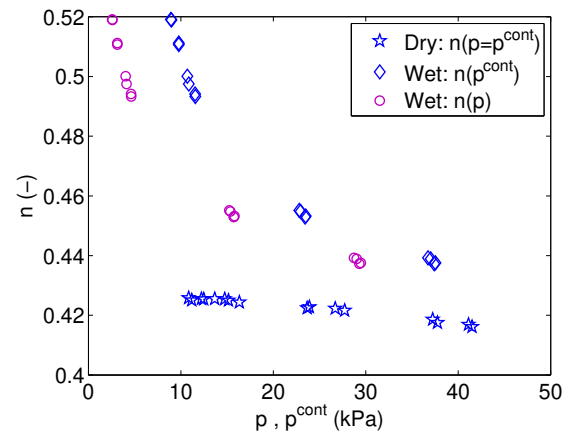

Figure 14: Critical state data for dry and wet triaxial compressions

compared with dry ones [48].

Interestingly, the $n$ vs. $p^{\text {cont }}$ CSL for wet conditions is also non-linear, as already observed from DEM in [49], while the dry CSL classically is, in the considered range of confining pressures. Logically, the numerical results in fact suggest that the wet CSL would eventually correspond to the dry CSL for very high confining pressures once the mechanical influence of partial saturation becomes negligible, i.e. when the capillary stress contribution to the total stress is small relative to the contact stress.

\section{Conclusion}

Multi-scale numerical simulations have brought new evidence on the existence of an effective stress variable for wet granular materials as the contact stress based on the action of intergranular contact forces. DEM results indeed show that dry constitutive relations applied to the latter may describe both failure and initial straining observed under unsaturated conditions in the pendular regime. Possible extension of the present approach outside the pendular regime would require other DEM models, such as those recently proposed by $[21,50]$.

While the present results suggest that another distinct effective stress variable is required to describe the complete mechanical behavior, as previously inferred in [43], a further exploration would be to try to generalize present results beyond the initial domain by explicitly decomposing the strain into various components, while herein only one strain variable that reflects all microscopic internal forces is being used. For instance, a "contact strain" and a "capillary strain" could be defined to represent the force contributions of contact and capillarity respectively to overall deformations. As such, the observed strains of unsaturated soils would be expressed as a combination of contact and capillary strains, while the dry constitutive relations would relate contact stress to contact strain throughout the whole behavior.

Moreover, it is to note that the contact stress requires the knowledge of intergranular contact forces which are readily computed in DEM models, but not 
easily accessible in dry real materials [19], not to mention the more interesting unsaturated case. In the latter case, the shortcoming can be circumvented by measuring the capillary stresses and, knowing the applied total stresses, the contact stresses would readily ensue by difference using Eq. (6). Indeed, microscale imaging techniques seem now capable of revealing the microstructure of fluid mixture during lab experiments [51], hence paving the way to an estimation of the capillary stresses, Eq. (5), in real materials, and ultimately the sought after contact stresses.

\section{Acknowledgments}

Some of the numerical results presented in the manuscript have been obtained by Nauman Hafeez Sultan, an undergraduate student from the University of Calgary, whose motivation is gratefully acknowledged. Discussions of ideas with Dr Nejib Hadda (University of Calgary) and Prof. Gaël Combe (University Grenoble Alps) were also appreciated. This work has been funded by the Natural Science and Engineering Research Council of Canada, and Foundation Computer Modelling Group.

\section{References}

[1] Terzaghi K. The shearing resistance of saturated soils and the angle between the planes of shear. Proceedings of the 1st International conference on soil mechanics and foundation engineering, vol. 1, Cambridge, 1936; 54-56.

[2] Bishop AW, Blight GE. Some aspects of effective stress in saturated and partly saturated soils. Géotechnique 1963; 13:177-197.

[3] Chateau X, Dormieux L. Homogenization of a non-saturated porous medium: Hill's lemma and applications. C. R. Acad. Sci. Paris, Série II 1995; 320:627-634.

[4] Chateau X, Dormieux L. Micromechanics of saturated and unsaturated porous media. International Journal for Numerical and Analytical Methods in Geomechanics 2002; 26(8):831-844, doi:10.1002/nag.227.

[5] Duriez J, Eghbalian M, Wan R, Darve F. The micromechanical nature of stresses in triphasic granular media with interfaces. Journal of the Mechanics and Physics of Solids 2017; 99:495-511, doi:10.1016/j.jmps.2016.10.011.

[6] Biot MA. General theory of three-dimensional consolidation. Journal of Applied Physics 1941; 12(2):155-164, doi:10.1063/1.1712886.

[7] Khalili N, Khabbaz MH. A unique relationship for $\chi$ for the determination of the shear strength of unsaturated soils. Géotechnique 1998; 48(5):681687, doi:10.1680/geot.1998.48.5.681. 
[8] Khalili N, Geiser F, Blight G. Effective stress in unsaturated soils: Review with new evidence. International Journal of Geomechanics 2004; 4(2):115126, doi:10.1061/(ASCE)1532-3641(2004)4:2(115).

[9] Lu N, Likos W. Suction stress characteristic curve for unsaturated soil. Journal of Geotechnical and Geoenvironmental Engineering 2006; 132(2):131-142, doi:10.1061/(ASCE)1090-0241(2006)132:2(131).

[10] Nuth M, Laloui L. Effective stress concept in unsaturated soils: Clarification and validation of a unified framework. International Journal for Numerical and Analytical Methods in Geomechanics 2008; 32(7):771-801, doi:10.1002/nag.645.

[11] Wan R, Duriez J, Darve F. A tensorial description of stresses in triphasic granular materials with interfaces. Geomechanics for Energy and the Environment 2015; 4:73-87, doi:10.1016/j.gete.2015.11.004.

[12] Duriez J, Wan R. Contact angle mechanical influence for wet granular soils. Acta Geotechnica 2017; 12(1):67-83, doi:10.1007/s11440-016-0500-6.

[13] Chareyre B. Comment on "Flow of wet granular materials: A numerical study". Phys. Rev. E 2017; 96:016 901, doi:10.1103/PhysRevE.96.016901.

[14] Scholtès L, Hicher PY, Nicot F, Chareyre B, Darve F. On the capillary stress tensor in wet granular materials. International Journal for Numerical and Analytical Methods in Geomechanics 2009; 33(10):1289-1313, doi:10. 1002/nag.767.

[15] Coussy O. Poromechanics. John Wiley \& Sons, 2004.

[16] Fredlund DG, Morgenstern NR, Widger RA. The shear strength of unsaturated soils. Canadian Geotechnical Journal 1978; 15(3):313-321, doi: $10.1139 /$ t78-029.

[17] Alonso EE, Gens A, Josa A. A constitutive model for partially saturated soils. Géotechnique 1990; 40(3):405-430.

[18] Alonso E, Pereira JM, Vaunat J, Olivella S. A microstructurally based effective stress for unsaturated soils. Géotechnique 2010; 60:913-925(12), doi:10.1680/geot.8.P.002.

[19] Hurley R, Marteau E, Ravichandran G, Andrade JE. Extracting interparticle forces in opaque granular materials: Beyond photoelasticity. Journal of the Mechanics and Physics of Solids 2014; 63:154 - 166, doi: 10.1016/j.jmps.2013.09.013.

[20] Gili JA, Alonso EE. Microstructural deformation mechanisms of unsaturated granular soils. International Journal for Numerical and Analytical Methods in Geomechanics 2002; 26(5):433-468, doi:10.1002/nag.206. 
[21] Melnikov K, Wittel FK, Herrmann HJ. Micro-mechanical failure analysis of wet granular matter. Acta Geotechnica 2016; 11(3):539-548, doi:10.1007/ s11440-016-0465-5.

[22] Duriez J, Wan R. Stress in wet granular media with interfaces via homogenization and discrete element approaches. Journal of Engineering Mechanics 2016; 142(12), doi:10.1061/(ASCE)EM.1943-7889.0001163.

[23] Love A. A treatise on the mathematical theory of elasticity. Cambridge: At the University Press, 1892.

[24] Parker EN. Tensor virial equations. Phys. Rev. 1954; 96:1686-1689, doi: 10.1103/PhysRev.96.1686.

[25] Duriez J, Wan R. Subtleties in discrete-element modelling of wet granular soils. Géotechnique 2017; 67(4):365-370, doi:10.1680/jgeot.15.P.113.

[26] Šmilauer V, et al.. Yade Documentation $2^{\text {nd }}$ ed. The Yade Project, 2015, doi:10.5281/zenodo.34073. URL http://yade-dem.org/doc/.

[27] Herminghaus S. Dynamics of wet granular matter. Advances in Physics 2005; 54(3):221-261, doi:10.1080/00018730500167855.

[28] Nova R. Liquefaction, stability, bifurcations of soil via strainhardening plasticity. Numerical Methods for Localisation and Bifurcation of Granular Bodies, $1989 ; 117-132$.

[29] Imposimato S, Nova R. An investigation on the uniqueness of the incremental response of elastoplastic models for virgin sand. Mechanics of Cohesivefrictional Materials 1998; 3(1):65-87.

[30] Darve F, Chau B. Constitutive instabilities in incrementally non-linear modelling. Constitutive Laws for Engineering Materials. Theory and Applications, Desai C, Krempl E, Kiousis P, Kundu T (eds.). Elsevier, 1987; 301-310.

[31] Daouadji A, Darve F, Gali HA, Hicher PY, Laouafa F, Lignon S, Nicot F, Nova R, Pinheiro M, Prunier F, et al.. Diffuse failure in geomaterials: Experiments, theory and modelling. International Journal for Numerical and Analytical Methods in Geomechanics 2011; 35(16):1731-1773, doi:10. 1002/nag.975.

[32] Duriez J, Darve F, Donzé FV, Nicot F. Material stability analysis of rock joints. International Journal for Numerical and Analytical Methods in Geomechanics 2013; 37(15):2539-2562, doi:10.1002/nag.2149.

[33] Roscoe KH, Schofield AN, Wroth CP. On the yielding of soils. Géotechnique 1958; 8:22-53(31). 
[34] Pouragha M, Wan R. Onset of structural evolution in granular materials as a redundancy problem. Granular Matter 2016; 18(3):1-13, doi:10.1007/ s10035-016-0640-2.

[35] Aharonov E, Sparks D. Stick-slip motion in simulated granular layers. Journal of Geophysical Research: Solid Earth 2004; 109(B9), doi:10.1029/ 2003JB002597. B09306.

[36] Tordesillas A, Muthuswamy M. On the modeling of confined buckling of force chains. Journal of the Mechanics and Physics of Solids 2009; 57(4):706 - 727, doi:10.1016/j.jmps.2009.01.005.

[37] Tordesillas A, Shi J, Tshaikiwsky T. Stress-dilatancy and force chain evolution. International Journal for Numerical and Analytical Methods in Geomechanics 2011; 35(2):264-292, doi:10.1002/nag.910.

[38] Doanh T, Hoang MT, Roux JN, Dequeker C. Stick-slip behaviour of model granular materials in drained triaxial compression. Granular Matter 2013; 15(1):1-23, doi:10.1007/s10035-012-0384-6.

[39] Darve F, Flavigny E, Meghachou M. Yield surfaces and principle of superposition: Revisit through incrementally non-linear constitutive relations. International Journal of Plasticity 1995; 11(8):927-948, doi:10.1016/ S0749-6419(95)00037-2.

[40] Roux JN, Combe G. Quasistatic rheology and the origins of strain. Comptes Rendus Physique 2002; 3(2):131 - 140, doi:10.1016/S1631-0705(02) 01306-3.

[41] Agnolin I, Roux JN. Internal states of model isotropic granular packings. III. Elastic properties. Phys. Rev. E 2007; 76:061304, doi:10.1103/ PhysRevE.76.061304.

[42] Roux JN, Combe G. How granular materials deform in quasistatic conditions. AIP Conference Proceedings 2010; 1227(1):260-270, doi:10.1063/1. 3435396.

[43] Coussy O, Pereira JM, Vaunat J. Revisiting the thermodynamics of hardening plasticity for unsaturated soils. Computers and Geotechnics 2010; 37(12):207-215, doi:10.1016/j.compgeo.2009.09.003.

[44] Darve F, Nicot F. On incremental non-linearity in granular media : phenomenological and multi-scale views (part i). International Journal for $\mathrm{Nu}$ merical and Analytical Methods in Geomechanics 2005; 29:1387-1409.

[45] Pouragha M, Wan R. Non-dissipative structural evolutions in granular materials within the small strain range. International Journal of Solids and Structures 2017; 110111:94 - 105, doi:10.1016/j.ijsolstr.2017.01.039. 
[46] Scott DR. Seismicity and stress rotation in a granular model of the brittle crust. Nature 1996; 381:592-595, doi:10.1038/381592a0.

[47] Jotisankasa A, Coop M, Ridley A. The mechanical behaviour of an unsaturated compacted silty clay. Géotechnique 2009; 59(5):415-428, doi: 10.1680/geot.2007.00060.

[48] Ishikawa T, Zhang Y, Tokoro T, Miura S. Medium-size triaxial apparatus for unsaturated granular subbase course materials. Soils and Foundations 2014; 54(1):67 - 80, doi:10.1016/j.sandf.2013.12.007. Special Issue on 2nd International Conference on Transportation Geotechnics IS-Hokkaido2012.

[49] Khamseh S, Roux JN, Chevoir F. Flow of wet granular materials: A numerical study. Phys. Rev. E 2015; 92:022 201, doi:10.1103/PhysRevE.92. 022201 .

[50] Yuan C, Chareyre B. A pore-scale method for hydromechanical coupling in deformable granular media. Computer Methods in Applied Mechanics and Engineering 2017; 318:1066-1079, doi:10.1016/j.cma.2017.02.024.

[51] Bruchon JF, Pereira JM, Vandamme M, Lenoir N, Delage P. X-ray microtomography characterisation of the changes in statistical homogeneity of an unsaturated sand during imbibition. Géotechnique Letters 2013; 3(2):8488, doi:10.1680/geolett.13.00013. 